\title{
Periodontal Therapy with $0.25 \%$ Lemongrass Oil Mouthwash in Reducing Risk of Cardiovascular Diseases: A 3-Arm Prospective Parallel Experimental Study
}

\author{
Dany Subha $S^{1 *}$, Tangde Pradeep ${ }^{2}$
}

\author{
OPEN ACCESS \\ Citation: Dany Subha S., Tangde \\ Pradeep. Periodontal Therapy in \\ Reducing Risk of Cardiovascular \\ Diseases. J Health Sci 2017;27(5):531. \\ doi:http://dx.doi.org/10.4314/ejhs.v27i4.1 \\ 2 \\ Received: December 29, 2016 \\ Accepted: Dember 31, 2016 \\ Published: September 1, 2017 \\ Copyright: (C) 2017 Dany Subha S., et al. \\ This is an open access article distributed \\ under the terms of the Creative Commons \\ Attribution License, which permits \\ unrestricted use, distribution, and \\ reproduction in any medium, provided the \\ original author and source are credited. \\ Funding: Nil \\ Competing Interests: The authors \\ declare that this manuscript was approved \\ by all authors in its form and that no \\ competing interest exists. \\ Affiliation and Correspondence: \\ ${ }^{1}$ Department of Dentistry, VSS \\ (Govt) Institute of Medical Sciences and \\ Research (VIMSAR), Burla, Odisha, \\ India \\ ${ }^{2}$ Department of Public Health Dentistry, \\ Teerthanker Mahaveer Institute of \\ Dental Sciences, Moradabad, Uttar \\ Pradesh, India \\ *Email: dr.subhamdany@gmail.com
}

\section{ABSTRACT}

BACKGROUND: Periodontal disease is associated with cardiovascular diseases because of its role in host immuneinflammatory response. Serum lipids are the commonest risk factors between periodontal disease and cardiovascular diseases.

MATERIALS AND METHOD: A double blinded randomised clinical trial was carried out among 45 subjects with generalised severe periodontitis. They were divided into 3-groups of 15 subjects each. Group A: $0.25 \%$ lemongrass oil mouthwash, Group B: $0.12 \%$ chlorhexidine mouthwash and Group C: Oral prophylaxis only Group. Oral examinations like assessment of Probing Pocket Depth and Clinical Attachment Loss and Bio-chemical tests like assessment of CReactive Protein, Total Cholesterol, High Density Lipid, Low Density Lipid and triglycerides were conducted at baseline followed by oral prophylaxis at the same visit. Reassessment of the above mentioned parameters were done after 3 months of intervention. Data so collected were subjected for statistical analysis using SPSS ver. 20.0.

RESULTS: A statistically significant reduction in C-Reactive Protein, Probing Pocket Depth, Clinical Attachment Loss, Total Cholesterol and Low Density Lipid level in $0.25 \%$ lemongrass oil mouthwash group was found. On comparing a statistically significant difference was observed for the post intervention scores of Probing Pocket Depth and Clinical Attachment Loss only; for Group A v/s C and Group B $v / s C$.

CONCLUSION: $0.25 \%$ Lemongrass oil mouthwash was found to be a good herbal alternative; both in the treatment of chronic periodontitis and reduction in the level of serum markers of Cardio Vascular Diseasess.

KEYWORDS: Non-surgical therapy, C-reactive protein, Lipid Profile

\section{INTRODUCTION}

Periodontitis is a chronic inflammatory disease of infectious nature (1). It may affect systemic inflammatory burden significantly, which would result in endothelial dysfunction, atherosclerotic plaque instability, dyslipidemia and insulin resistance depending on the severity of periodontitis (2). Several studies indicated that subjects with periodontal disease may have a higher risk for cardiovascular 
diseases (CVDs) when compared to subjects with a healthy periodontium (3).

Periodontitis has been strongly associated with elevation of systemic inflammatory markers, such as C-reactive protein (CRP) (4), which is considered as an independent predictor of cardiovascular disease (CVDs) (5), including coronary heart disease (CHD) (6). C-reactive protein levels are elevated in severe chronic periodontitis subjects, and most intervention studies reported that periodontal treatment decreased the levels of systemic inflammatory cytokines in systemic healthy subjects.

Hyperlipidaemia is a state with an abnormal lipid profile, which is characterized by elevated blood concentrations of triglycerides, elevated levels of total cholesterol and Low Density Lipoprotein (LDL) and decreased levels of High Density Lipoprotein (HDL) cholesterol (7). Periodontitis related atherogenic alterations are also associated with lipoprotein metabolism (8).There are common risk factors for periodontal disease. and CVDs. Serum lipids may be the most important among these factors (9). According to Katz J et al. (10) hyper-cholesterolaemia and CVDs are related to periodontal disease.

Essential oils are ideal for use in oral care products because they are both antibacterial and nontoxic - a rare combination. Mouth washes containing essential oils are used for many years in the prevention and treatment of periodontal disease. Recent studies demonstrated that essential oil mouthwashes are as effective as chlorhexidine mouthwash in inhibiting the plaque regrowth (11) as they can penetrate the plaque biofilm, kill the pathogenic micro-organisms by disrupting their cell wall and inhibiting their enzymatic activity (12). Essential oil mouthwash prevents bacterial aggregation, slows their multiplication and extracts the bacterial endotoxins (13). The mechanisms by which essential oils can inhibit microorganisms may be due to their hydrophobicity, as a result of which they get partitioned into the lipid bilayer of the cell membrane, making it more permeable, leading to leakage of vital cell contents (14). Impairment of bacterial enzyme systems may also be a potential mechanism of action (15).
Lemongrass oil is an essential oil, extracted from Lemon grass which belongs to the section of Andropogan called Cymbopogam of the family Germineae. The two of the major species are Cymbopogan citrates and C. flexuosus (16). It has a plethora of medicinal uses; antibacterial, antifungal, antioxidant, antiseptic, astringent, antiinflammatory, analgesic, antipyretic and carminative property (17), and its antibacterial and antifungal properties are comparable to that of penicillin in its effectiveness (18).

An intra-oral source of infection like periodontitis can create an inflammatory immune response, thereby placing an apparently healthy individual at an increased risk for CVD. Periodontal disease can be treated and the risk of developing CVD can be reduced (19). Therefore, with a background of plaque control as a key factor for prevention of periodontal diseases, limited effectiveness of mechanical plaque control and linking the faith of people for herbal/natural products and potency of lemongrass oil the present study was conducted. The aim was to investigate efficacy of non-surgical periodontal therapy with $0.25 \%$ lemongrass oil mouthwash in reducing the risk of Cardiovascular Diseases [CVDs] in chronic periodontitis patients.

\section{MATERIALS AND METHOD}

This double blinded randomised controlled parallel designed clinical trial was planned with patients attending Kothiwal Dental College and Research Centre, Moradabad; following CONSORT guidelines for clinical trials (20). Based on a pilot study, to get a clinically significant difference between the groups, the necessary sample size was estimated using sample size and power calculations developed by William D. Dupont and licensed under a Creative Commons Attribution-Non Commercial-No Derivs 3.0 United States License.(21). A sample size of 12 subjects in each group was estimated considering 5\% type I error and 20\% type II error. Originally, 15 subjects were recruited in each group forecasting some amount of loss to followup during the course of the study.

Ethical clearance for the study was obtained from the Institutional Ethical Committee of

DOI: http://dx.doi.org/10.4314/ejhs.v27i5.12 
Kothiwal Dental College and Research Centre, Moradabad in India, and the examiner was calibrated so as to achieve a minimum kappa value of 0.80 for inter- and intra-examiner consistency. In order to ensure this, 5 patients were randomly selected and examined and re-examined for the Probing Pocket Depth (PPD) and Clinical Attachment Loss (CAL). The kappa value for intra-examiner reliability was found to be 0.85 and 0.88 respectively. The examiner was trained to match the ability of a gold standard examiner, to check for this, inter-examiner reliability testing was done for PPD and CAL of the same patients. The kappa statistics for this was found to be 0.82 and 0.86 respectively.

The inclusion criteria for the study was set as: patients aged 30- 50 years with generalized severe periodontitis (CAL: $>4 \mathrm{~mm}$ with minimum of $30 \%$ affected site). Patients with any systemic diseases, is known to have allergy for lemongrass derivatives, had received any antibiotic treatment 6 months prior to the study, unable to comply with the follow-up visit requirements, undergoing orthodontic treatment or any other treatment that may affect periodontal health, pregnant and nursing patients and patients who are suffering from oral disease that need emergency treatment like endo-perio lesion, periodontal abscess were excluded.

A study sample of 45 patients who fulfilled the inclusion and exclusion criteria were recruited. Prior to recruitment, these subjects were made to sign informed consent after being described about the nature, potential risks and benefits of their participation in the study.

All the 45 patients were randomly divided into 3 equal groups (Figure 1) by a periodontal expert who was not involved with the study to ensure blindingby balloting. They were also not aware of other parallel groups or mouthwashes used in this study. After that, the subjects were advised to follow thof their respective groups and were asked to report to the department again after 3 months.

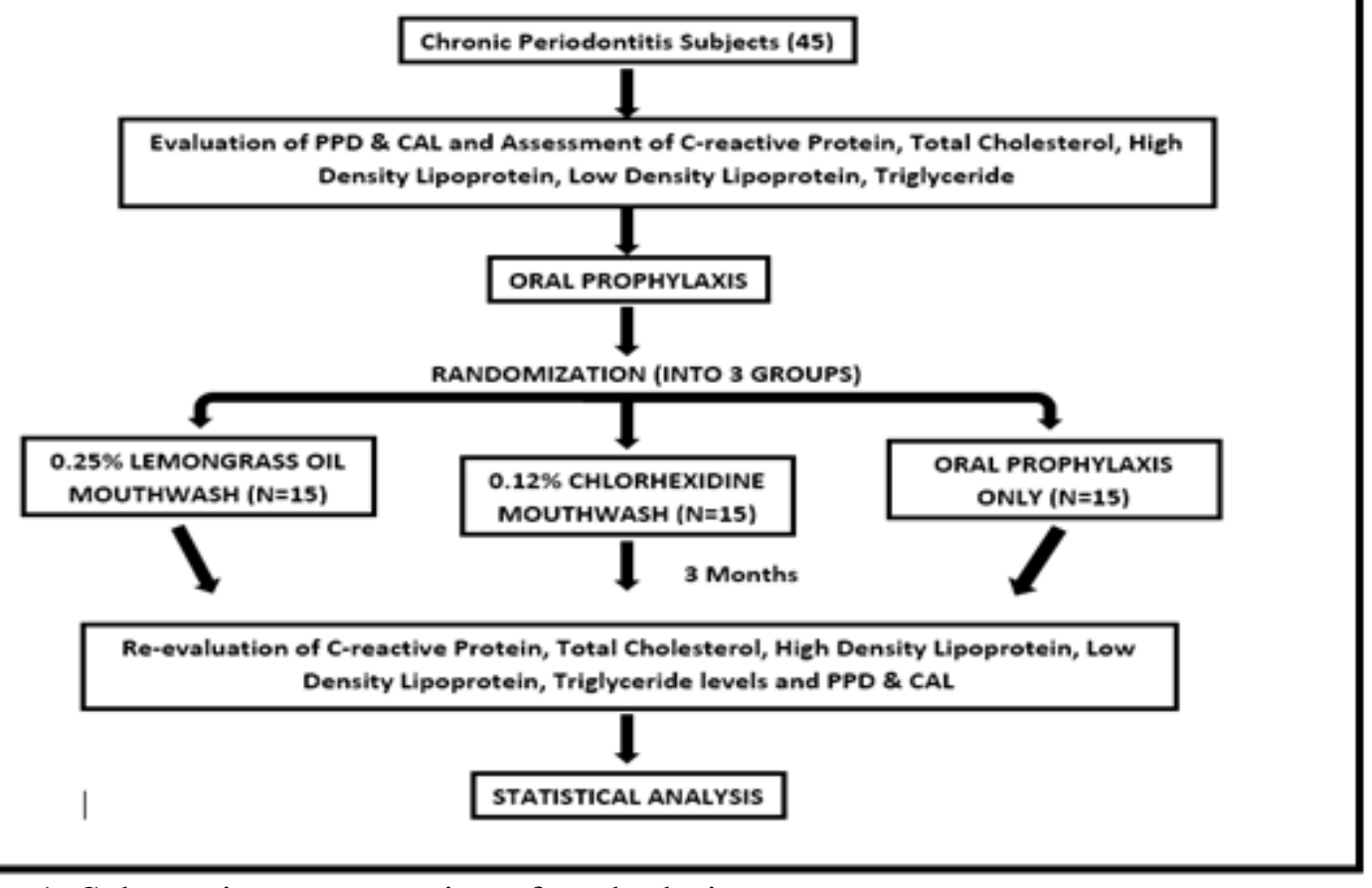

Figure 1: Schematic representation of study design. 
Group A: Lemongrass oil $(0.25 \%)$ mouthwash Group (n=15): Lemongrass oil mouthwash was prepared using the standard protocol in Department of Pharmacology, Kothiwal dental college and research centre. Patients were instructed to use $0.25 \%$ lemongrass oil mouthwash twice daily for 1 minute for 3 months. Group B: Chlorhexidine $(\mathbf{0 . 1 2 \%})$ mouthwash Group $(\mathbf{n}=15)$ : Patients were supplied with commercially available $0.12 \%$ chlorhexidine mouthwash. They were instructed to use it twice daily for 1 minute for 3 months. Group C: Oral prophylaxis only Group (n=15): Patients were advised brushing with proper brushing technique being taught by a Periodontist. They were asked to brush twice daily: in the morning and last thing at night for 2-3 minutes for 3 months. Group A and B were also instructed for the same brushing technique and regime along with use of mouthwashes for the entire study period.

Modified bass technique was demonstrated to the subjects, and they were also supplied with new toothbrushes of same make and brand to maintain the uniformity at the commencement of the experimental period. The participants were instructed by the examiner on the use of mouthwash and brushing, and regular performance was reinforced every 3 days through telephone calls to ensure compliance.

The oral examinations were conducted in the Department Of Public Health Dentistry, and biochemical tests were done in the Department of General Pathology, Kothiwal Dental College and Research Centre, Moradabad. Oral examination included assessing PPD, and CAL and Biochemical tests done were assessment of CRP,
Total Cholesterol, HDL, LDL and triglycerides at baseline followed by oral prophylaxis at the same visit; subjects were again assessed after 3 months' of intervention.

Statistical analysis was carried out using SPSS ver. 20.0 (SPSS, Inc., Chicago, IL, USA). Levene's test for homogeneity of variance $(P<0.05)$ was performed, as we assumed equity of variance was more important than an assumption of normality. Hierarchical regression analysis was done to establish association between the independent variables and $\mathrm{C}$ - reactive protein in chronic periodontitis subjects. A comparison of the mean differences of the variables at baseline and post-intervention was analyzed by a paired $t$ test and between the groups by one-way analysis of variance (ANOVA). Post hoc test (Tukey's Test) was done to identify the significant pairs. Level of significance was set at $\mathrm{p} \leq 0.05$ (95\% confidence interval).

\section{RESULTS}

Study subjects consisted of 45 individuals (Male: 26, Female: 19) with chronic periodontitis. The mean age of the subjects was $43.52 \pm 4.63$. Table 1 shows the mean distribution of CRP, TC, TG, HDL, LDL, PPD and CAL in Chronic Periodontitis subjects. Table 2 shows the hierarchical regression analysis done to find out the association between the independent variables and $\mathrm{C}$ - reactive protein in chronic periodontitis subjects $(\mathrm{N}=45)$. In the first model, only lipid profile parameters were taken into consideration,

Table 1: Mean distribution of $\mathrm{C}$ - reactive protein, lipid profile and periodontal parameters in chronic periodontitis subjects

\begin{tabular}{lc}
\hline \multicolumn{1}{c}{ Variables } & Mean \pm SD \\
\hline C- reactive protein (mg/L) & $1.75 \pm 0.69$ \\
Probing Pocket Depth (PPD) (mm) & $5.12 \pm 0.58$ \\
Clinical Attachment Loss (CAL) $(\mathrm{mm})$ & $5.29 \pm 0.56$ \\
Total Cholesterol (mg/dl) & $216.27 \pm 38.70$ \\
Triglycerides (mg/dl) & $168.20 \pm 31.53$ \\
High Density Lipoprotein (HDL) (mg/dl) & $41.04 \pm 16.60$ \\
Low Density Lipoprotein (LDL) $(\mathrm{mg} / \mathrm{dl})$ & $140.04 \pm 29.20$ \\
\hline
\end{tabular}

DOI: http://dx.doi.org/10.4314/ejhs.v27i5.12 
and this model was found to be statistically significant and total cholesterol was found out to be associated significantly with $\mathrm{C}$ - reactive protein. In the second model, along with lipid profile parameters, PPD and CAL were introduced into the first model. This model was also found to be statistically significant. Total cholesterol along with PPD and CAL were found to be significantly associated with $\mathrm{C}$ - reactive protein.

Table 3 shows the comparison of mean changes in $\mathrm{C}$ - reactive protein, lipid profile and periodontal parameters among all the three groups. It shows a statistically significant reduction in CRP, PPD, CAL, TC and LDL along with a significant increase in HDL level in the $0.25 \%$ lemongrass oil mouthwash group. On comparing between the groups, statistically significant difference was found for the post-intervention scores of PPD and CAL only, the significantly different groups being Group A v/s Group C and Group B v/s Group C for both PPD and CAL.

Table 2: Hierarchical regression analysis showing the association between the independent variables and $\mathrm{C}$ - reactive protein in chronic periodontitis subjects $(\mathrm{N}=45)$

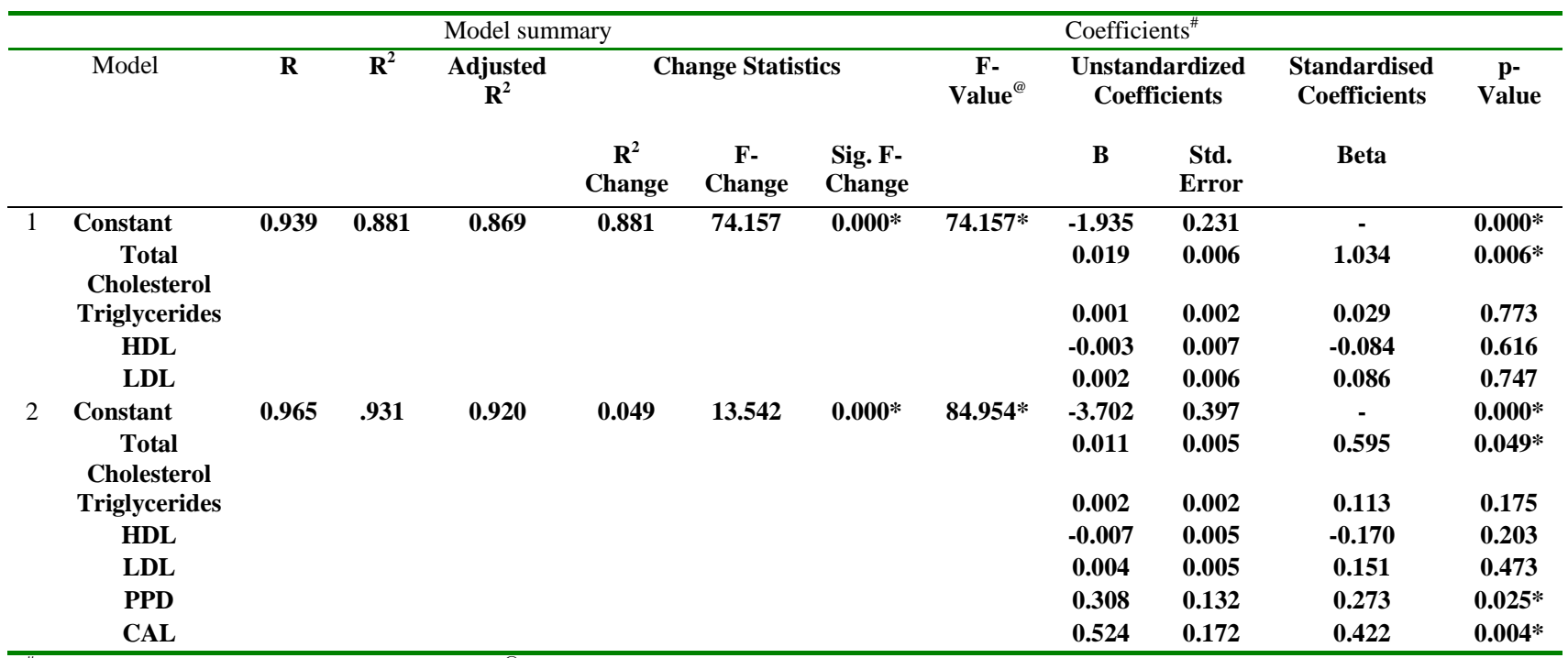

${ }^{\#}$ Dependent variable C- reactive protein, ${ }^{@}$ ANOVA , * $\mathrm{p}<0.05$; Statistically Significant

\section{DISCUSSION}

This prospective double-blinded parallel designed clinical trial was conducted to investigate efficacy of non-surgical periodontal therapy with $0.25 \%$ lemongrass oil mouthwash in reducing the risk of Cardiovascular Diseases [CVDs] in the study participants. Comparisons were also made with gold standard $0.12 \%$ chlorhexidine mouthwash and oral prophylaxis only as control groups. To overcome the Hawthorne effect, these control groups were chosen (22).

Hierarchical regression analysis in this study showed a statistically significant positive association between severity of periodontal disease (PPD, CAL) and CRP level. This was in agreement with prior evidence from epidemiological studies by Slade et al, (23). The possible mechanisms that connect focal infection in periodontitis with systemic cytokine levels might be that; the Tumor Necrosis Factor (TNF)- $\alpha$ stimulated the expression of Interleukin (IL)-6, which consequently augmented the CRP gene expression in the liver (24). Low levels of bacteremia may provide a stimulus for systemic inflammatory responses such as increased production of CRP due to activation of the cascade of inflammatory cytokine production by monocytes and other cells in the periodontal tissue and elsewhere (25). 
Table 3: Comparison of mean changes in C- reactive protein, lipid profile and periodontal parameters among all the three groups

\begin{tabular}{|c|c|c|c|c|c|c|c|}
\hline \multicolumn{2}{|c|}{ VARIABLES } & \multicolumn{3}{|c|}{ Mean \pm Standard Deviation } & \multirow[t]{2}{*}{ F-value ${ }^{€}$} & \multirow{2}{*}{$\begin{array}{c}\mathrm{p}- \\
\text { value }\end{array}$} & \multirow[t]{2}{*}{ Significant Pairs $^{\#}$} \\
\hline & & Group A $(N=15)$ & Group B $(\mathrm{N}=15)$ & Group $\mathrm{C}(\mathrm{N}=15)$ & & & \\
\hline \multirow[t]{4}{*}{ C- reactive protein $(\mathrm{mg} / \mathrm{L})$} & Baseline & $1.77 \pm 0.69$ & $1.72 \pm 0.72$ & $1.74 \pm 0.72$ & 0.017 & 0.983 & - \\
\hline & 3 months & $1.69 \pm 0.65$ & $1.66 \pm 0.68$ & $1.71 \pm 0.68$ & 0.018 & 0.982 & - \\
\hline & $\Delta(\%)$ & $0.08 \pm 0.09(4.51)$ & $0.06 \pm 0.07(3.48)$ & $0.03 \pm 0.06(1.72)$ & - & - & - \\
\hline & t- Value ${ }^{\$}$ (Significance) & $3.66(\mathrm{p}=0.003)^{*}$ & $3.15(\mathrm{p}=0.007)^{*}$ & $1.74(p=0.104)$ & - & - & - \\
\hline \multirow{4}{*}{$\begin{array}{l}\text { Probing Pocket Depth (PPD) } \\
\qquad(\mathrm{mm})\end{array}$} & Baseline & $5.12 \pm 0.55$ & $5.13 \pm 0.66$ & $5.11 \pm 0.66$ & 0.002 & 0.998 & - \\
\hline & 3 months & $4.46 \pm 0.55$ & $4.48 \pm 0.60$ & $5.03 \pm 0.03$ & 4.402 & $0.018^{*}$ & $\begin{array}{l}\text { A \& C }(p=0.032) \\
\text { B \& C }(p=0.040)\end{array}$ \\
\hline & $\Delta(\%)$ & $0.66 \pm 0.19(12.89)$ & $0.65 \pm 0.21(12.67)$ & $0.08 \pm 0.07(1.56)$ & - & - & - \\
\hline & t- Value ${ }^{\$}$ (Significance) & $13.06(\mathrm{p}=0.000)^{*}$ & $11.74(\mathrm{p}=0.000)^{*}$ & $4.58(\mathrm{p}=0.000)^{*}$ & - & - & - \\
\hline \multirow{4}{*}{$\begin{array}{l}\text { Clinical Attachment Loss } \\
\text { (CAL) }(\mathrm{mm})\end{array}$} & Baseline & $5.31 \pm 0.58$ & $5.26 \pm 0.59$ & $5.32 \pm 0.54$ & 0.050 & 0.951 & - \\
\hline & 3 months & $4.75 \pm 0.54$ & $4.71 \pm 0.53$ & $5.23 \pm 0.55$ & 4.311 & $0.020^{*}$ & $\begin{array}{l}\text { A \& C }(p=0.049) \\
\text { B \& C }(p=0.031)\end{array}$ \\
\hline & $\Delta(\%)$ & $0.56 \pm 0.19(10.54)$ & $0.55 \pm 0.19(10.45)$ & $0.09 \pm 0.05(1.69)$ & - & - & - \\
\hline & t- Value ${ }^{\$}$ (Significance) & $11.69(\mathrm{p}=0.000)^{*}$ & $11.37(\mathrm{p}=0.000)^{*}$ & $7.90(\mathrm{p}=0.000)^{*}$ & - & - & - \\
\hline \multirow[t]{4}{*}{ Total Cholesterol (mg/dl) } & Baseline & $216.07 \pm 44.61$ & $216.80 \pm 40.36$ & $215.93 \pm 32.97$ & 0.002 & 0.998 & - \\
\hline & 3 months & $185.20 \pm 45.64$ & $198.60 \pm 36.52$ & $205.27 \pm 32.88$ & 1.045 & 0.361 & - \\
\hline & $\Delta(\%)$ & $30.87 \pm 8.89(14.28)$ & $18.20 \pm 9.86(8.42)$ & $10.67 \pm 0.89(4.94)$ & - & - & - \\
\hline & t- Value ${ }^{\$}$ (Significance) & $13.45(\mathrm{p}=0.000)^{*}$ & $7.15(\mathrm{p}=0.000)^{*}$ & $45.92(\mathrm{p}=0.000)^{*}$ & - & - & - \\
\hline \multirow[t]{4}{*}{ Triglycerides (mg/dl) } & Baseline & $169.13 \pm 34.98$ & $164.40 \pm 30.71$ & $171.07 \pm 30.55$ & 0.171 & 0.844 & - \\
\hline & 3 months & $151.13 \pm 48.19$ & $130.20 \pm 31.14$ & $164.67 \pm 41.55$ & 2.704 & 0.079 & - \\
\hline & $\Delta(\%)$ & $18.00 \pm 40.61(10.64)$ & $\begin{array}{c}34.20 \pm 39.44 \\
(20.80)\end{array}$ & $6.40 \pm 41.16(3.74)$ & - & - & - \\
\hline & t- Value ${ }^{\$}$ (Significance) & $1.72(\mathrm{p}=0.108)$ & $3.36(\mathrm{p}=0.005)^{*}$ & $0.602(0.557)$ & - & - & - \\
\hline \multirow{4}{*}{$\begin{array}{l}\text { High Density Lipoprotein } \\
\text { (HDL) }(\mathrm{mg} / \mathrm{dl})\end{array}$} & Baseline & $44.00 \pm 19.61$ & $36.67 \pm 11.64$ & $42.47 \pm 17.73$ & 0.807 & 0.453 & - \\
\hline & 3 months & $45.60 \pm 19.65$ & $37.47 \pm 12.44$ & $42.73 \pm 16.90$ & 0.927 & 0.404 & - \\
\hline & $\Delta(\%)$ & $1.6 \pm 2.26(3.63)$ & $0.80 \pm 3.17(2.18)$ & $0.27 \pm 1.91(0.62)$ & - & - & - \\
\hline & t- Value ${ }^{\$}$ (Significance) & $2.74(0.016)^{*}$ & $0.98(0.344)$ & $0.541(0.597)$ & - & - & - \\
\hline \multirow{4}{*}{$\begin{array}{l}\text { Low Density Lipoprotein } \\
\text { (LDL) }(\mathrm{mg} / \mathrm{dl})\end{array}$} & Baseline & $135.27 \pm 33.11$ & $145.93 \pm 31.19$ & $138.93 \pm 23.00$ & 0.505 & 0.607 & - \\
\hline & 3 months & $109.60 \pm 33.85$ & $134.93 \pm 31.94$ & $129.60 \pm 25.98$ & 2.861 & 0.068 & - \\
\hline & $\Delta(\%)$ & $25.67 \pm 13.31(18.97)$ & $11.00 \pm 6.19(7.53)$ & $9.33 \pm 9.22(6.71)$ & - & - & - \\
\hline & t- Value ${ }^{\$}$ (Significance) & $7.97(\mathrm{p}=0.000)^{*}$ & $6.89(\mathrm{p}=0.000)^{*}$ & $3.91(\mathrm{p}=0.000)^{*}$ & - & - & - \\
\hline
\end{tabular}

$\mathrm{p}<0.05$; Statistically Significant; ${ }^{\$}$ Paired t-test; ${ }^{\epsilon}$ ANOVA; ${ }^{\#}$ Tukey's test; $\Delta$ Difference between baseline and 3 month's score. 
Post-treatment, CRP levels reduced in all the 3 groups, but the reduction was significant only in case of the groups who were given either of the two mouthwashes post oral prophylaxis. After periodontal therapy, some residual sites may have remained, and there may have been insufficient time for bio-chemical changes to be established after disease reduction. These results could also mean that non-surgical periodontal therapy alone was not able to bring down chronic inflammatory stimulus in these subjects. Reduction in CRP postperiodontal therapy was consistent with previous studies by Tuter et al. (26) and Hussainet al (27). Highest reduction in CRP level was found in the $0.25 \%$ lemongrass oil mouthwash group. This can be attributed to Citral, a component of lemongrass oil, which activates Peroxisome ProliferatorActivated Receptor (PPAR) $\alpha$ and $\gamma$ and suppresses expression of COX-2 (28).

Local infection is considered to be a contributor to the systemic inflammation burden. In this study, post non-surgical periodontal treatment there has been significant reduction in PPD and CAL; so are the reduction in systemic markers of infection and lipid profile parameters. The statistically significant, highest reduction in PPD and CAL was seen in $0.25 \%$ lemongrass oil mouthwash group. From the results of this study, it can be implied that the lemongrass oil mouthwash can have an adjunctive effect on the treatment outcome used along with non-surgical periodontal therapy. This may be attributed to the fact that lemongrass essential oil could inhibit the growth of several kinds of microorganisms at a concentration less than or equal to $2 \%$. The antioxidant activity of lemongrass oil the result of its contents such as citral (neral and geranial) and citronellal (29). In this study, both antimicrobial and antioxidant activities were achieved by using $0.25 \%$ lemongrass essential oil in the mouthwash formulation.

Citral can subside oxidative stress through Glutathione (GSH)'s antioxidant system induction because of its steroisomer, neral and geranial (30). It can also act via terminating the chain reaction of lipid metabolism by donating hydrogen to free radical (31). Flavonoid, a chemical component of lemongrass oil has many biological activities, viz., antioxidant, anti-inflammatory, antimicrobial, antimutagenic and anti tumour (32). Therefore, its activity can evade oxidation reaction along with reducing hydroxyl radical, peroxyl radical and superoxide (33). Citral is not only an active component of lemongrass oil but also helps in formation of Vitamin $\mathrm{A}$ and $\mathrm{C}$; which are secondary antioxidants to scavenge free radicals and also prevents damage by stopping chain reaction (34).

Lipopolysaccharides of dental plaque diffuse into the systemic circulation and they elicit a systemic lipopolysaccharide specific antibody response. This may lead to lipid metabolism disturbance and a hypercoagulable state through elevation of circulating cytokines (35). A possible explanation for the association between hyperlipidaemia and periodontal infection was postulated by Noack et al (36) by assessing neutrophil respiratory burst by whole blood chemiluminescence, and they found significant increases in both chemiluminescence and pocket depth on a group of patients with hyperlipidaemia. They suggested that the association of hyperlipidaemia with periodontitis could be due to the dysfunction of polymorphonuclear leukocytes.

The result of this study shows that local periodontal treatment resulted in significant decrease in TC, LDL, and a significant rise in HDL level in the $0.25 \%$ lemongrass oil mouthwash group. In the $0.12 \%$ chlorhexidine group, there was a significant reduction in serum TC, LDL, and TG and in oral prophylaxis group only TC and LDL levels were significantly reduced. The reduction of TC, LDL, TG and the rise in HDL after treatment suggests a potential effect of periodontitis-driven systemic inflammation on lipid metabolism. These findings are in accordance with a report by Pussinen et al (37) and Rao et al, (38) who reported that periodontitis is associated with a reduction of the HDL levels and that periodontal therapy results in an increase in this anti-atherogenic lipid fraction. However, in another study conducted by D'Aiuto et al, (39) lipid marker changes were insignificant between standard periodontal treatment and control groups. Though some reductions of TC and LDL were present only in the intensive 
periodontal treatment group. There have been studies which reported that periodontal treatment is associated with the reduction of proatherogenic plasma lipid levels, i.e. TC and LDL as well as TG in patients with severe periodontitis $(39,40)$. Lemongrass oil decreases the level of TNF- $\alpha$ and IL-1, thus increasing production of lipoprotein lipase causing betterment in lipid metabolism (35).

In conclusion, this clinical trial was limited by its small sample size and duration to cause change in systemic inflammatory markers. Therefore, large studies and clinical intervention trials are necessary to define whether these findings are true or are confounded by other important factors like nutrition, socioeconomic status or age. From a larger scale study, a better and precise comparison can be achieved. Within its limitations, this study indicated that nonsurgical periodontal therapy in chronic periodontitis patients could cause significant changes in the concentration of total cholesterol, triglyceride, HDL, LDL and C-Reactive Protein levels in blood serum.

Lemongrass oil $(0.25 \%)$ mouthwash was found to be a good herbal alternative to $0.12 \%$ chlorhexidine mouthwash. It can be an adjunct to non-surgical periodontal therapy both in the treatment of chronic periodontitis and reduction in the level of serum markers of CVDs. As it is one of the very few studies on the use of lemongrass oil as an active agent in mouthwash, so further studies on it with various other parameters are needed to know more of its beneficial and unfavourable (if any) effects.

\section{REFERENCES}

1. Tatakis DN, Kumar PS. Etiology and pathogenesis of periodontal diseases. Dental Clinics of North America 2005;49:491516.

2. Pradeep AR, Kumari M, Kalra N, et al. Correlation of MCP-4 and high-sensitivity C-reactive protein as a marker of inflammation in obesity and chronic periodontitis. Cytokine 2013; 61:772-777.

3. Beck JD, Offenbacher S, Williams R, Gibbs P, Garcia R. Periodontitis, a risk factor for coronary heart disease? Ann Periodontol 1998.;3:127-141.

4. Paraskevas S, Huizinga JD, Loos BG. A systematic review and meta-analyses on C-reactive protein in relation to periodontitis. J ClinPeriodontol 2008; 35:277-290.

5. Wang Z. Hoy WE. C-reactive protein: an independent predictor of cardiovascular disease in Aboriginal Australians. Australian and New Zealand Journal of Public Health 2010; 34 (Suppl 1), S25-29.

6. Wang TJ, Larson MG, Levy D, Benjamin EJ, Kupka MJ, Manning WJ, Clouse ME, D'Agostino RB, Wilson PW, O'Donnell CJ. C-reactive protein is associated with subclinical epicardial coronary calcification in men and women: the Framingham Heart Study. Circulation 2002; 106: $1189-1191$

7. Saito T, Shimazaki Y. Metabolic disorders related to obesity and periodontal disease. Periodontology 2000 2007; 43: 254-266.

8. Pussinen PJ, Mattila K. Periodontal infections and atherosclerosis: Mere associations? CurrOpinLipidol.2004; 15: 583-588.

9. Izumi A, Yoshihara A, Hirotomi T, Miyazaki $H$. The relationship between serum lipids and periodontitis in elderly non-smokers. J Periodontol.2009; 80: 740-748.

10. Katz J, Chaushu G, Sharabi Y. On the association between hypercholesterolemia, cardiovascular disease and severe periodontal disease. $J$ Clin Periodontol.2001; 28: 865-868.

11. Riep BG, Bernimoulin JP, Barnett ML. Comparative antiplaque effectiveness of an essential oil and an amine fluoride/stannous fluoride mouthrinse. $J$ ClinPeriodontol.1999; 26:164.

12. Ouhayoun JP. Penetrating the plaque biofilm: impact of essential oil 
mouthwash. J ClinPeriodontol 2003; 30(5):10-12.

13. Seymour R. Additional properties and uses of essential oils. J ClinPeriodontol 2003; 30(5):19-21.

14. Burt S. Essential oils: their antibacterial properties and potential applications in foods - a review. Int J Food Microbiol 2004;94:223-53.

15. Wendakoon, C. N. and Sakaguchi, M. Inhibition of amino acid decarboxylase activity of Enterobacter aerogenes by active components of spices. Journal of Food Protection 1995, 58, 280-283.

16. Atal CK, Kapur BM. Cultivation \& Utilization of aromatic plants. Regional Res. Labs. CSIR Jammu 1982;314-17.

17. Anonymous. The wealth of India (Raw material). CSIR India 1950;11:411-15.

18. Lutterodt GD, Ismail A, Basheer RH, Baharudin HM. Antimicrobial effect of psidiumguajava extract as one mechanism of its antidiarhoealacion. Malay $\mathrm{J}$ Med Sci.1999; 6(2):17-20.

19. Ide M, McPartlin D, Coward PY, Crook M, Lumb P, Wilson RF. Effect of treatment of chronic periodontitis on levels of serum markers of acute phase inflammatory and vascular responses. $J$ ClinPeriodontol.2003; 30: 334-340.

20. Kenneth F S, Douglas G A, David M. CONSORT 2010 Statement: updated guidelines for reporting parallel group randomised trials. BMJ 2010;340:c332.

21. Dupont WD, Plummer WD Jr. 2014; Available at: http://biostat.mc.vanderbilt. edu/wiki/Main/PowerSampleSize. Last accessed on 18.12.14.

22. Moeintaghavi A, Arab HR, Bozorgnia Y, Kianoush K, Alizadeh M. Non-surgical periodontal therapy affects metabolic control in diabetics: a randomized controlled clinical trial. Aust Dent J.2012; 57:31-37.
23. Slade GD, Offenbacher S, Beck JD, Heiss G, Pankow JS. Acute phase response to periodontal disease in the US population. $J$ Dent Res 2000; 79;49-57.

24. Goncalves TO, Costa D, Brodskyn CI et al. Release of cytokines by stimulated peripheral blood mononuclear cells in chronic periodontitis. Arch Oral Biol 2010;55:975-980.

25. Genco RJ. Periodontal disease: A possible risk factor for myocardial infarction and cardiovascular disease. Cardiovasc Rev Rep 1998; 19: 34-40.

26. Tuter G, Kurtis B, Serdar M, et al. Effects of scaling and root planning and subantimicrobial dose doxycycline on oral and systemic biomarkers of disease in patients with both chronic periodontitis and coronary artery disease. $J$ ClinPeriodontol 2007; 34:673-681.

27. Hussain BS, Khan AA, Tatakis DN, et al. Non-surgical periodontal therapy lowers serum inflammatory markers: a pilot study. J Periodontol 2009;80:1574-1580.

28. Katsukawa M, Nakata R, Takizawa Y et al. Citral, a component of lemongrass oil, activates PPAR $\alpha$ and $\gamma$ and suppresses COX-2 expression. BiochimicaetBiophysicaActa 2010; 1801:1214-1220.

29. Susanto SA, Oktavianti TA, Wijaya Y, Wira V, Paramitta VA. Increased glutathione level in saliva of moderate gingivitis patients after lemongrass (cymbopogoncitratus) essential oil gargling. Asia Pac Dent Stud J 2010.; $1: 45-52$.

30. Nakamura Y, Miyamoto M, Murakami A, Ohigashi H, Osawa T, Uchida K. A Phase II Detoxification Enzyme Inducerfrom Lemongrass: Identification of Citral and Involvement of Electrophilic Reaction in the Enzyme Induction. BiochemBiophys Res Commun.2003; 302:593-600. 
31. Shahidi F, Wanasundara PKJPD. Phenolic Antioxidants: Critical Review. Critical Reviews in Food Science and Nutrition 1992; 32:67-103.

32. Crawford M, Hanson SW, Moustapha ES, Koker A. The Structure of Cymbopogon, A Novel Trterpenoid from Lemongrass. Tetrahedron Letter 1975.; 35:3099-128.

33. Harun N, Syari W. Aktivitas Antioksidan Ekstrak Daun Dewadalam Menghambatsifat Hepatotoksik Halotandengan Dosis Subanestesipada Mencit. Jurnal Sainsdan Teknologi Farmasi.2002;7(2):63-70.

34. Kumalaningsih S. Antioksidan, SumberdanManfaatnya. 2007. Available at: http://antioxidantcentre.com. Last accessed on 10.12.14.

35. Wu T, Trevisan M, Genco RJ, Falkner KL, Dorn JP, Sempos CT. Examination of the relation between periodontal health status and cardiovascular risk factors: serum total and high density lipoprotein cholesterol, C-reactive protein, and plasma fibrinogen. $A m \quad J \quad$ Epidemiol $2000 ; 151(3): 273-82$
36. Noack B, Genco RJ, Trevisan M, et al. Periodontal infections contribute to elevated systemic C-reactive protein level. J Periodontol 2001; 72:1221-1227.

37. Pussinen PJ, Jauhiainen M, VilkunaRautiainen T, Sundvall J, Vesanen M, Mattila K. Periodontitis decreases the antiatherogenic potency of high density lipoprotein. J Lipid Res 2004; 45:139.

38. Rao NS, Bajaj P, Naik SB, Pradeep AR. Effect of non surgical periodontal therapy on serum lipid levels in chronic periodontitis. Archives of Oral Sciences and Research 2011; 1(2):60-64.

39. D'aiuto F, Nibali L, Parkar M, Suvan J, Tonetti MS. Short-term effects of intensive periodontal therapy on serum inflammatory markers and cholesterol. $J$ Dent Res 2005;84:269-73.

40. Lösche W, Marshal GJ, Apatzidou DA, Krause S, Kocher T, Kinane DF. Lipoprotein-associated phospholipase A2 and plasma lipids in patients with destructive periodontal disease. $J$ Clin Periodontol 